OPEN ACCESS

Edited by:

Qingfeng Zhang,

Tongji University, China

Reviewed by:

Xindong $X U$,

Tongji University, China

Yang Hong,

Chinese Academy of Agricultural

Sciences (CAAS), China

*Correspondence:

Gang-Long Yang

glyanglife@jilangnan.edu.cn

Kun Yang

yangkun@jipd.com

Specialty section:

This article was submitted to

Parasite and Host,

a section of the journal

Frontiers in Cellular and

Infection Microbiology

Received: 27 September 2021 Accepted: 26 November 2021

Published: 22 December 2021

Citation:

Bi N-N, Zhao S, Zhang J-F, Cheng $Y$, Zuo C-Y, Yang G-L and Yang K (2021)

Proteomics Investigations of Potential Protein Biomarkers in Sera of Rabbits Infected With Schistosoma japonicum. Front. Cell. Infect. Microbiol. 11:784279. doi: 10.3389/fcimb.2021.784279

\section{Proteomics Investigations of Potential Protein Biomarkers in Sera of Rabbits Infected With Schistosoma japonicum}

\author{
Nian-Nian $\mathrm{Bi}^{1}$, Song Zhao ${ }^{2,3}$, Jian-Feng Zhang ${ }^{2}$, Ying Cheng $^{3}$, Chen-Yang Zuo ${ }^{3}$, \\ Gang-Long Yang ${ }^{3 *}$ and Kun Yang ${ }^{1,2 *}$
}

${ }^{1}$ School of Public Health, Nanjing Medical University, Nanjing, China, ${ }^{2}$ National Health Commission (NHC) Key Laboratory of Parasitic Disease Control and Prevention, Jiangsu Provincial Key Laboratory on Parasite and Vector Control Technology, Jiangsu Institute of Parasitic Diseases, Wuxi, China, ${ }^{3}$ The Key Laboratory of Carbohydrate Chemistry \& Biotechnology, Ministry of Education, School of Biotechnology, Jiangnan University, Wuxi, China

Schistosomiasis is a chronic parasitic disease that continues to be a pressing public health problem in many developing countries. The primary pathological damage from the disease is granuloma and fibrosis caused by egg aggregation, and early treatment can effectively prevent the occurrence of liver fibrosis. Therefore, it is very important to identify biomarkers that can be used for early diagnosis of Schistosoma japonicum infection. In this study, a label-free proteomics method was performed to observe the alteration of proteins before infection, 1 and 6 weeks after infection, and 5 and 7 weeks after treatment. A total of 10 proteins derived from S. japonicum and 242 host-derived proteins were identified and quantified as significantly changed. Temporal analysis was carried out to further analyze potential biomarkers with coherent changes during infection and treatment. The results revealed biological process changes in serum proteins compared to infection and treatment groups, which implicated receptor-mediated endocytosis, inflammatory response, and acute-phase response such as mannanbinding lectin serine peptidase 1, immunoglobulin, and collagen. These findings offer guidance for the in-depth analysis of potential biomarkers of schistosomiasis, host protein, and early diagnosis of $S$. japonicum and its pathogenesis. Data are available via ProteomeXchange with identifier PXD029635.

Keywords: Schistosoma japonicum, proteomics, label free, biomarker, bioinformatics

\section{INTRODUCTION}

Schistosomiasis is a chronic zoonotic parasitic disease that affects at least 78 countries and regions, and hundreds of millions of people are at risk of infection (LoVerde, 2019). Thus, it is of great public health significance. Schistosoma japonicum is one of the pathogens of human schistosomiasis, which is mainly distributed in Asia, in countries such as China, the Philippines, and Indonesia (Gryseels et al., 2006; McManus et al., 2018). The pathological damage caused by S. japonicum is mainly liver and portal vein system damage (Carson et al., 2018; Hu et al., 2020). After mating, paired 
schistosomes residing in the mesenteric vein could produce a large number of eggs that accumulate in the liver and result in liver granulomas, progressing to liver fibrosis (McManus et al., 2018). Even if the adults in the host are eliminated, the serious pathological damage caused by granulomas is difficult to reverse (Hu et al., 2020), and therefore, identifying and testing potential candidate biomarkers for the treatment of schistosomiasis is of high priority.

At present, the gold standard for the diagnosis of S. japonicum continues to be the Kato-Katz method (McManus et al., 2018), in which fecal smears are examined under a microscope for the presence of eggs. Other diagnostic methods, such as serological diagnosis, detect soluble egg antigens (McManus et al., 2018; Hu et al., 2020) by antigen-antibody reaction, and molecular biological methods detect $S$. japonicum nucleic acid fragments (Weerakoon et al., 2017) by polymerase chain reaction (PCR). However, due to the limitations of sensitivity, specificity, cost, and field application, it is difficult for these methods to achieve early diagnosis of S. japonicum infection. Additionally, it is difficult to distinguish whether the infection is active or not (Gryseels et al., 2006; Bergquist et al., 2009). With the migration of blood in the host, S. japonicum secretes excreta into the blood (Deelder et al., 1980) when feeding on red blood cells. The origin of circulating cathodic antigen and circulating anodic antigen is that it has a positive or negative charge at neutral $\mathrm{pH}$ according to its electrophoretic mobility which is called CCA and CAA (Casacuberta et al., 2016). They can be detected by enzymelinked immunosorbent assay (ELISA) or lateral flow analysis based on monoclonal antibodies (McManus et al., 2018). These two antigens are markers of active infection of Schistosoma and can be detected (van Dam et al., 1996) when they are not spawned in the early stage of infection, and therefore, they can be used as potential serum biomarkers after infection.

The development of proteomics technology has enabled researchers to quickly obtain a large amount of human physiological and pathological information (Karczewski and Snyder, 2018) by evaluating biomarkers to distinguish diseases and determine the rules of pathological changes (Bojkova et al., 2020; Puray-Chavez et al., 2021). The proteomics related to $S$. japonicum mainly focus on secretory proteins, parasites, and proteomics at various developmental stages (Cheng et al., 2005; Liu et al., 2009; Hong et al., 2013; Cao et al., 2016a; Cao et al., 2016b; De Marco Verissimo et al., 2019; Li et al., 2020), while there have been relatively few studies on the changes in the host during the disease (Shiff et al., 2006). In addition, the entire proteome of unisexual infected female worms (FSS) and bisexual infected mature female worms (FMS) of S. japonicum was studied by iTRAQ and liquid chromatography-tandem mass spectrometry (LC-MS/MS) techniques. The differentially expressed proteins (DEP) were identified and analyzed, and the role of DEPs in sexual maturation and reproductive development of S. japonicum (Li et al., 2020) was further analyzed.

Serum, as a repository of secreted proteins from organs of the entire body, reflects the pathological and physiological changes in the body, which may include biomarkers of disease and treatment (Geyer et al., 2017). Because S. japonicum excretes secretory proteins (Deelder et al., 1980) in the host, there may be parasitic or host-related biomarkers in serum proteins after infection. Kardoush et al. (2016) identified a large number of candidate hosts and parasite biomarkers of acute and chronic schistosomiasis in mice by combining surface-enhanced laser desorption ionization-time of flight mass spectrometry (SELDITOF MS), matrix-assisted, laser desorption and ionization (MALDI-TOF MS), and Orbitrap techniques in the serum proteome of Schistosoma mansoni, and they verified the protein glutathione S-transferase (GST:25KDa), which can be used as a potential biomarker for early diagnosis. Onile et al. (Onile et al., 2017) selected proteomic methods to find several parasite- and host-specific protein biomarkers in a clinical urine sample cohort, which may have diagnostic potential in urine detection of schistosomiasis and schistosomiasis-related bladder cancer in Egypt. Proteomics has been successfully used in the testing and identification of biomarkers for a variety of diseases. It is an effective means to explore and verify the differences in the occurrence and development of diseases by combining mass spectrometry and bioinformatics.

In this study, a label-free proteome shotgun method was used to screen differential proteins in the serum after infection with $S$. japonicum and treatment. Then, we explored potential biomarkers by dynamic protein expression changes occurring in the host proteome in response to Schistosoma infection and treatment.

\section{MATERIAL AND METHODS}

\section{Ethics Statement}

All animal experiments were conducted in strict accordance with the guidelines of the International Association for Assessment and Accreditation of Laboratory Animal Care (IAAALAC). The protocol was approved by the Ethical Review Committee of Jiangsu Institute of Parasitic Diseases (JIPD) [permit ID JIPD2020-013].

\section{Pretreatment of Serum Protein Samples}

In this experiment, four New Zealand rabbits $(\mathrm{n}=4)$, weighing 2.0-2.5 kg, were used as experimental subjects to observe the changes in proteins before infection, after infection, and after treatment. First, New Zealand rabbits were infected by abdominal patch with 1,000 cercariae of S. japonicum. The cercariae were provided by the Jiangsu Institute of Parasitic Diseases. All rabbit stool samples were examined by the miracidium hatching test (Yu et al., 2007; He et al., 2018), and the presence of miracidia confirmed the success of infection. The serum was collected before infection (Ctrl group) as a negative control (Guo et al., 2012) as well as 1 week (E1w) and 6 weeks (E6w) postinfection. After 7 weeks of infection, praziquantel (PZQ) $(150 \mathrm{mg} / \mathrm{kg})$ was orally administered for 2 days, and the serum was collected at 5 weeks (T5w) and 7 weeks $(\mathrm{T} 7 \mathrm{w})$ after treatment. No adults were found in the portal system 16 weeks posttreatment after sacrificing the rabbits by humane methods. The peripheral blood was collected through the ear vein. 
After the samples were collected, the serum was separated in a thermostat at $37^{\circ} \mathrm{C}$ for $4 \mathrm{~h}$. The serum was centrifuged for $5 \mathrm{~min}$ at $200 \times \mathrm{g}$ and then stored at $-80^{\circ} \mathrm{C}$. For the serum sample preparation of each group, equal volumes of four biological repetitive serum samples were pooled into one group (Schwamborn et al., 2009), from which three technical repeats were produced. A volume of 60 $\mu \mathrm{l}$ of pooled serum sample from each group was processed using the ProteoExtract Albumin/IgG Removal Kit (Merck Millipore, Billerica, MA, USA). According to the commercial instructions for the kit, albumin and IgG in high abundance were removed to reduce the complexity of the serum (Xing et al., 2019). After removal of high-abundance proteins, the serum protein was concentrated in a $10-\mathrm{kDa}$ centrifugation ultrafiltration tube (Amicon Ultra-0.5, Millipore, MA, USA), and the concentrated protein was obtained by $13,000 \times \mathrm{g}$ centrifugation for $5 \mathrm{~min}$. Using a BCA kit (Beyotime, Shanghai, China) and bovine serum albumin (BSA) as the standard, a standard curve was determined by SpectraMax i3 (Molecular Devices, USA) at $562 \mathrm{~nm}$, and the concentration of the sample was calculated.

\section{Digestion of Serum Proteins}

Serum proteins were denatured in $8 \mathrm{mM}$ urea/40 $\mathrm{mM} \mathrm{NH}_{4} \mathrm{HCO}_{3}$ buffer with protease inhibitors (100×; Beyotime, Shanghai, China). Proteins were added with $10 \mathrm{mM}$ dithiothreitol (DTT) for $60 \mathrm{~min}$ at room temperature (RT) and then alkylated by 20 $\mathrm{mM}$ iodoacetamide (IAM) for $45 \mathrm{~min}$ in the dark at RT. The solution was buffer-exchanged with $40 \mathrm{mM} \mathrm{NH}_{4} \mathrm{HCO}_{3}$ to dilute 8 -fold with a $10-\mathrm{kDa}$ centrifugation ultrafiltration tube.

According to the manufacturer's instructions, proteolytic digestion was performed by the addition of $30 \mu$ l Sequencing Grade Modified Trypsin (Promega, Madison, WI) (enzyme: protein ratio of 1:50 w/w) and incubation while shaking at 500 $\mathrm{rpm}$ and $37^{\circ} \mathrm{C}$ for $12 \mathrm{~h}$. Then, $7.5 \mu \mathrm{l}$ trypsin was added so that the final ratio was $1: 40$ trypsin, with incubation at $37^{\circ} \mathrm{C}$ for $4 \mathrm{~h}$. After restriction endonuclease digestion, 50\% formic acid (FA) (v/v) was used for acidification, and dilution with $0.1 \%$ FA (v/v) was performed to terminate the trypsin reaction, with subsequent centrifugation at $13,000 \times \mathrm{g}$ for $15 \mathrm{~min}$. The supernatant was collected, and the peptide concentration was measured using the NanoDrop 2000c spectrophotometer (Thermo Scientific, USA).

The polypeptide (Yang et al., 2018) was purified by C18 solidphase extraction. First, $50 \mu \mathrm{g}$ peptide solution was transferred to the internally prepared tip column. The tip column was cleaned with acetonitrile (ACN), 0.1\% FA/50\% ACN (v/v), and $0.1 \%$ trifluoroacetic acid (TFA) (v/v). After injection, the sample was washed with $1 \%$ FA (v/v). Finally, the sample was collected with $0.1 \% \mathrm{FA} / 50 \% \mathrm{ACN}(\mathrm{v} / \mathrm{v})$. Appropriate volumes of the peptides (three independent replicates from five groups) were evaporated to dryness using a freeze-dryer (Labconco, USA).

\section{LC-MS/MS Analysis}

Freeze-dried peptides were suspended in $0.1 \% \mathrm{FA} / 2 \% \mathrm{ACN}(\mathrm{v} / \mathrm{v})$ before MS analysis. The peptide was diluted to $0.5 \mu \mathrm{g} / \mu \mathrm{l}$, and the suspension was vortexed for $1 \mathrm{~min}$ and centrifuged for $10 \mathrm{~min}$ at $13,000 \times g$. The Easy-nLC 1200 system (Thermo Science, San Jose, CA, USA) and high-resolution Orbitrap Fusion Lumos spectrometer (Thermo Science, San Jose, CA) were used for analysis. Each injection volume was $3 \mu \mathrm{l}$. The samples were first separated on an Easy-nLC 1200 system with an RSLC C18 column $(1.9 \mu \mathrm{m} \times 100 \mu \mathrm{m} \times 20 \mathrm{~cm})$. The mobile phase buffer $\mathrm{A}$ is water, and the buffer $\mathrm{B}$ is $90 \% \mathrm{ACN}$. The flow rate is set to $550 \mathrm{nl} / \mathrm{min}$. The data-dependent high-energy collision dissociation (HCD) fragmented the 20 most abundant ions. The spray voltage was in static mode. The spectrum (the AGC target was $4.0 \mathrm{e} 5$, and the maximum injection time was $50 \mathrm{~ms}$ ) was collected in the range of $350-2,000 \mathrm{~nm}$ pulse $\mathrm{z}$ with a resolution of 60,000 , followed by data-related higher-energy collisional dissociation (HCD)-MS/MS (resolution of 30,000, collision energy of $34 \%$, step collision energy of $5 \%$, target of 5.0e4, maximum injection time of $35 \mathrm{~ms}$, microscan 1). Charge state screening can reject single charge ions and ions with more than eight charges. A dynamic exclusion time of $45 \mathrm{~s}$ was used to distinguish newly selected ions from previously selected ions.

\section{Statistical Analysis of Mass Spectrometry}

All the original MS data were processed using MaxQuant software (version 1.6.14.0) and its built-in search engine Andromeda, and the databases for $S$. japonicum and New Zealand rabbits from UniProt (downloaded on 09/23/2020) were used for peptide recognition and protein inference. The false discovery rate (FDR) at both the peptide and protein levels was set at $1 \%$. The key settings were digestion enzyme: trypsin/p, and tolerated missed cleavage: 2 . Carbamidomethyl $(\mathrm{C},+57 \mathrm{Da})$ was set as fix modification, and Oxidation $(\mathrm{M},+16 \mathrm{Da})$ modification was included as a variable modification. In other LC-MS operations, peptide identification was converted to unidentified characteristics based on the quality of the match and the retention time of the run-to-run recalibration (the "match between run" option in MaxQuant). Label-free quantification (LFQ) using MaxQuant requires at least one peptide ratio (Cox et al., 2014) for each identified protein, based on the determination of the median paired common peptide ratio between samples. The LFQ value for MaxQuant was imported into Perseus software (version 1.6.14.0). The proteins were initially filtered with "potential contaminant" and "reverse." Proteins identified with at least one unique peptide were considered for further data analysis. Samples were then grouped into experimental and Ctrl groups, and only proteins with two valid values in at least one group were retained.

Based on the assumption that the strength of most peptides was constant between samples, the peptide strength was normalized to minimize the overall proteome difference. The logarithmic conversion of proteome LFQ intensity was performed to reduce the effect of outliers. The missing value was replaced by a random value generated by the Gaussian distribution to simulate the lowabundance LFQ value, and each sample in the distribution with a width of 0.3 and a downward shift of 1.8 was calculated. The logarithmic ratio (fold change) was calculated according to the difference in the average $\log _{2}$ LFQ intensity between the experimental groups and the Ctrl group. The proteins that were significantly up- or downregulated (two-sided, unpaired Student's $t$ test with equal variance assumed, $\mathrm{p}$-adjust $<0.05, \mathrm{n}=3,\left|\log _{2} \mathrm{FC}\right|>\mid$ $\log _{2} 1.5 \mid$ ) in at least one infected sample compared with the corresponding Ctrl are shown. The data were standardized using $\mathrm{Z}$-scoring before row-wise clustering and plotting. In the statistical 
test, double-tailed, unpaired, and equal-variance Student's $t$-test calculations using Benjamin \& Hochberg correction were carried out using LFQ data. Statistical analysis and visualization of differential expression were performed by hierarchical clustering and principal component analysis (PCA). Heat maps and PCA maps were generated by Pheatmap ( $\mathrm{R}$ packet), status ( $\mathrm{R}$ packet), and ggplot2. The host differential proteins were enriched by GO function using the cluster profiler ( $\mathrm{R}$ package). The proteins identified as those of $S$. japonicum provide BLAST results of protein sequences between $S$. japonicum and rabbit to ensure the results and underwent GO function annotation (Conesa et al., 2005; Sotillo et al., 2015) by Blast2GO. The mass spectrometry proteomics data have been deposited to the ProteomeXchange Consortium via the PRIDE (Perez-Riverol et al., 2019) partner repository with the dataset identifier PXD029635.

\section{RESULTS}

\section{The Host Proteome Changed After Infection and Treatment}

After infection and treatment, five groups of samples (Ctrl, E1w, E6w, T5w, and T7w) were analyzed to identify candidate biomarkers for infection and treatment of schistosomiasis. In this study, a total of 682 proteins were identified using a label- free shotgun proteomics approach. Nearly all the identified proteins $(98.53 \%)$ were from host samples, and only 11 proteins were uniquely derived from $S$. japonicum. For the host, a total of 671 proteins were identified from the Ctrl, E1w, E6w, T5w, and T7w samples (Supplementary Table 1). The Venn diagram in Figure 1A shows that 367 proteins were commonly identified in the five groups, in which the number of proteins was 546, 491, 531, 432 , and 532, respectively. Regarding proteins identified in only one group, 22 proteins were exclusively identified in the Ctrl group, 4 in E1w, 28 in E6w, 2 in T5w, and 28 in the T7w group. Venn diagrams (Figures 1B, C) show the overlaps between the $\mathrm{Ctrl}$, the groups after infection, and the groups after treatment.

To quantitatively analyze the proteins from the five groups and discover potential biomarkers during Schistosoma infection and treatment, the intensity of proteins was applied and filtered with the following parameters based on label-free quantitative proteomics: samples were grouped into Ctrl and four experimental groups, and only proteins with two valid values in at least one group were retained. Finally, 396 high-quality proteins were selected for the next steps. The principal component analysis (PCA) highlighted the high degree of reproducibility among three replicates and clearly classified the five groups (Figure 1D). PCA1 and PCA2 accounted for $33.31 \%$ and $15.2 \%$ of the principal components, respectively. It was suggested that the infection of S. japonicum and praziquantel treatment obviously affected the protein expression

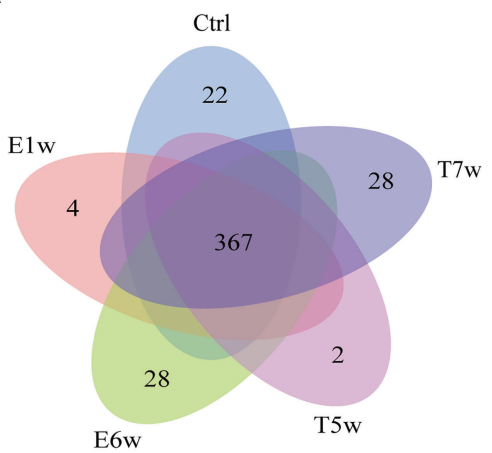

C

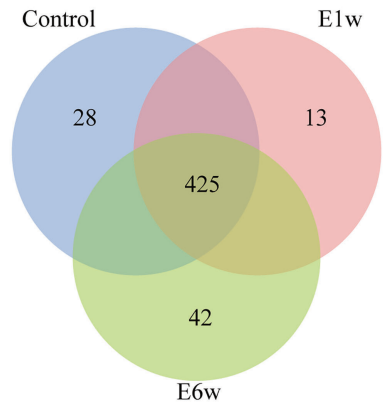

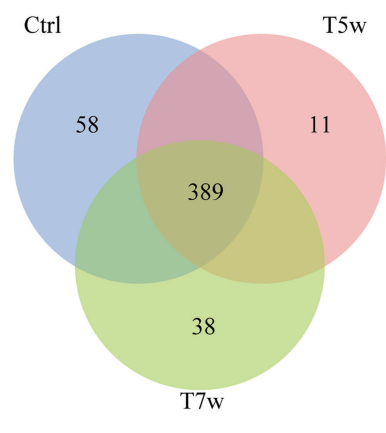

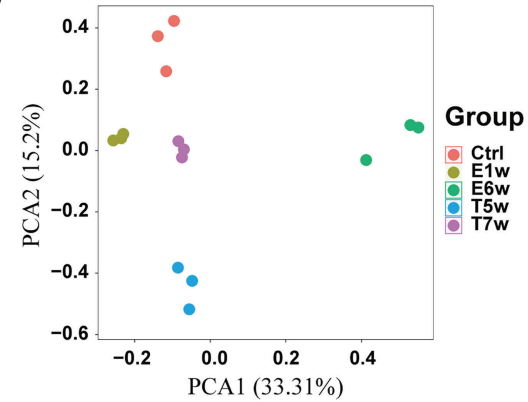

FIGURE 1 | Host proteins changed after Schistosoma japonicum infection and treatment. (A) Venn diagram of the identified host proteins in the five groups, Ctrl, E1w, E6w, T5w, and T7w. (B) Overlap proteins after treatment. (C) Overlap proteins after infection. (D) PCA analysis of host proteins. 
and secretion of the host rabbit. There were differences between the proteomes of the five studied groups.

Of note, methods revealed that the E6w group differed the most from the other groups, indicating that the protein expression profile encountered a major shift in the E6w group. Furthermore, we compared the protein expression between the four experimental groups and the Ctrl group (Figure 2A), as well as two consecutive groups (Figure 2B). It was found that a total of 242 proteins significantly changed after infection or treatment. Compared with the Ctrl, the differential protein increased over time, reached a peak at 6 weeks after infection, and then began to decrease after treatment.

\section{Identification of S. japonicum-Derived Protein in the Host Serum}

A total of 11 Schistosoma unique proteins in host serum were identified when the raw data were searched against a combination database of rabbit (taxid:9986) and S. japonicum (taxid:6182). Considering that there was suppression by highly abundant proteins in the MS identification, the data were also searched against the S. japonicum (taxid:6182) database only, as described in a previous study (Onile et al., 2017), and 45 Schistosoma proteins were identified (Supplementary Table 2). Therefore, the search results for the two methods were combined for further analysis of proteins derived from S. japonicum.

Venn diagrams were generated to identify proteins unique to each group and the overlaps of identified S. japonicum proteins. Out of 11 Schistosoma proteins searched against a combination database of rabbit and S. japonicum, 3, 0, 0, 1, and 4 proteins were unique to Ctrl, E1w, E6w, T5w, and T7w, respectively, and 1 protein was found common to all studied groups (Figure 2C). When searching the database of S. japonicum only, 7, 0, 6, 3, and 17 proteins were unique to Ctrl, E1w, E6w, T5w, and T7w, respectively, and 6 proteins were found common to all studied groups (Figure 2D). Due to many conservative proteins between $S$. japonicum and rabbit, the proteins identified from $S$. japonicum in the Ctrl group were removed. The "unique peptide" of $S$. japonicum identified by blastp through NCBI using default settings (Park et al., 2009), and the "organism" contained rabbit (taxid:9986) and S. japonicum (taxid:6182). According to the maximum of "MaxScore," the "scientific name" of proteins distinguished the proteins of $S$. japonicum or rabbit. Ten proteins derived from $S$. japonicum include tubulin, calmodulin, EF-hand domain-containing protein, and SJCHGC06596 protein, etc. It has been predicted that they have molecular functions such as calcium ion binding, GTP binding, and DNA binding. The GO terms of the identified Schistosoma proteins are summarized in Table $\mathbf{1}$.

\section{Host Protein Expression Landscape Temporal Analysis}

To obtain a temporal change in the host proteins during five points after infection and treatment, we analyzed system-wide differences in protein levels over time. Comparison of host proteins allowed us to dissect the contribution of the Schistosoma infection and treatment to changes in the host proteomics. We found that 242 host proteins were differentially expressed in the samples of five groups after correlating their expression with infection and treatment.

To address our hypothesis that during infection and treatment of $S$. japonicum, some meaningful proteins underwent temporal
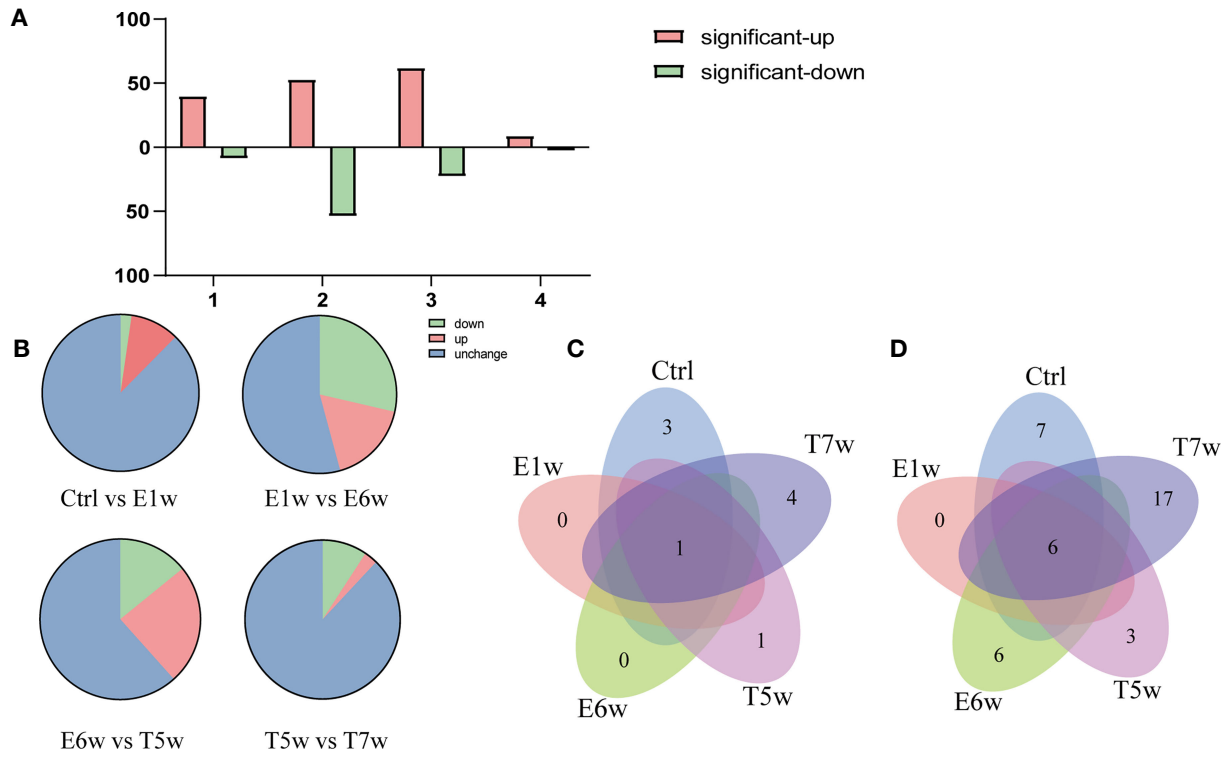

FIGURE 2 | Numbers of upregulated or downregulated DEPs changed when comparing four experimental groups (A) with the Ctrl group and (B) between two consecutive groups. (C) Venn diagram of the identified Schistosoma-derived proteins searched against a combination database of rabbit and S. japonicum in the five groups, Ctrl, E1w, E6w, T5w, and T7w. (D) Venn diagram of the identified Schistosoma-derived proteins searched S. japonicum database only in the five groups, Ctrl, E1w, E6w, T5w, and T7w. 
TABLE 1 | BLAST results between S. japonicum and rabbit and Gene ontology analysis of Schistosoma-derived proteins.

\begin{tabular}{|c|c|c|c|c|c|c|}
\hline Sequence & UniProt ID & Description & $\begin{array}{c}\text { Max } \\
\text { score }\end{array}$ & $\begin{array}{c}E \\
\text { value }\end{array}$ & $\begin{array}{c}\text { Sequence } \\
\text { coverage } \\
{[\%]}\end{array}$ & GO terms \\
\hline IALEQAR & AOA4Z2CWQ3 & $\begin{array}{l}\text { Translin-associated factor } \mathrm{X} \text {-interacting } \\
\text { protein isoform } 2\end{array}$ & 24.8 & 0.45 & 0.9 & F:calcium ion binding \\
\hline DGVPDIVILVDSGNTQQLQVILR & A0A4Z2CXV5 & T-cell immunomodulatory protein & 75.3 & $\begin{array}{l}1.00 \mathrm{E}- \\
17\end{array}$ & 3.5 & $\begin{array}{l}\text { P:integrin-mediated signaling } \\
\text { pathway; C:integral component of } \\
\text { membrane }\end{array}$ \\
\hline DVNAAIATIK & A0A4Z2D895 & Tubulin alpha-3 chain & 33.3 & $\begin{array}{c}8.00 E- \\
04\end{array}$ & 32 & $\begin{array}{l}\text { F:GTPase activity; C:cytoplasm; P: } \\
\text { cytoskeleton organization; }\end{array}$ \\
\hline EDILYSHLK & A0A4Z2DER5 & $\begin{array}{l}\text { Phosphatidylinositol 4-phosphate 3- } \\
\text { kinase C2 domain-containing subunit } \\
\text { alpha }\end{array}$ & 32.9 & 0.001 & 0.4 & $\begin{array}{l}\text { F:kinase activity; P: } \\
\text { phosphorylation; }\end{array}$ \\
\hline SLQNANVIQTLR & A0A4Z2DIC3 & $\begin{array}{l}\text { Phosphatidylinositol-binding clathrin } \\
\text { assembly protein }\end{array}$ & 40.5 & $\begin{array}{c}3.00 E- \\
06\end{array}$ & 0.7 & $\begin{array}{l}\text { F:1-phosphatidylinositol binding; C: } \\
\text { cilium; P:clathrin coat assembly }\end{array}$ \\
\hline ADQLTEEQIAEFKEAFSLFDKDGDGTITTK & A0A4Z2DTY8 & Calmodulin & 97.3 & $\begin{array}{l}8.00 E- \\
25\end{array}$ & 20.8 & $\begin{array}{l}\text { F:calcium ion binding; C: } \\
\text { cytoplasm; P:protein } \\
\text { phosphorylation }\end{array}$ \\
\hline VTYDGILGNSALEMTK & Q5DCJ5 & SJCHGC06596 protein & 53.7 & $\begin{array}{c}2.00 \mathrm{E}- \\
10\end{array}$ & 4.5 & F:nucleotide binding; C:ribosome; \\
\hline EAFSLIDQNR & Q5DFN5 & EF-hand domain-containing protein & 35.4 & $\begin{array}{l}1.00 E- \\
04\end{array}$ & 9.8 & F:calcium ion binding \\
\hline AVEIKELEGLPGDVLR & AOA4Z2DRZ9 & DNA-directed RNA polymerase & 52.4 & $\begin{array}{c}4.00 E- \\
10\end{array}$ & 1.5 & $\begin{array}{l}\text { F:DNA binding; C:nucleus; P: } \\
\text { transcription, DNA-templated; }\end{array}$ \\
\hline LSDDEPLLEK & C1LFK2 & Peptidase M & 34.6 & $\begin{array}{c}3.00 E- \\
04\end{array}$ & 6.1 & $\begin{array}{l}\text { C:chromatin; F:double-stranded } \\
\text { DNA binding; P:response to UV }\end{array}$ \\
\hline
\end{tabular}

B, biological process; $M$, molecular function; C, cell component.

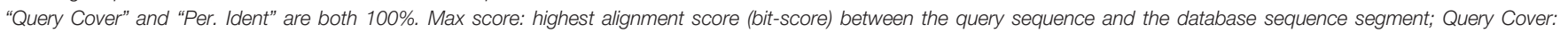
percentage of the query length that is included in the aligned segments. This coverage is calculated over all segments.

change, we used HCA analysis to identify protein groups or clusters that demonstrated a similar temporal pattern (Figure 3A). Unsupervised clustering defined eight unique clusters that characterized the temporal regulation of the proteome. The $\mathrm{k}$ means method is useful to cluster proteins into a specified number of classes based on the similarity of temporal profiles. We applied the k-means algorithm and manual selection to group all DEPs into eight distinct clusters for identification of potential proteins dysregulated during Schistosoma infection (Figure 3B). Clusters 3 and 4 represent proteins that are downregulated, and cluster 8 represents proteins that are upregulated, whereas other clusters represent proteins displaying a bimodal expression pattern, such as a decrease in E6w (clusters 1 and 2) or a gradual increase in E6w (clusters 7 and 8). Among eight clusters, two clusters were upregulated at 1 week after infection, and cluster 7 returned to normal levels after treatment. Clusters 5 and 6 were downregulated at 1 week after infection, which increased at 6 weeks after infection, and decreased with the extension of treatment time. Overall, most of the differentially expressed proteins increased following Schistosoma infection, with proteins in cluster 2 displaying the greatest fold changes.

\section{GO Analysis of Different Protein Profiles}

To determine the biological significance of these DEPs, GO enrichment analysis was performed for every cluster. To obtain a global overview of the types of DEPs, they were also classified into three clusters by gene ontology (GO): cellular component, molecular function, biological process, and protein class. We found that the proteins present in each profile enriched distinct biological processes and molecular function (Supplementary Table 1). One of the most rapid changes in early infection was cluster 7, which consisted of 18 proteins that exhibited striking upregulation at $\mathrm{E} 1 \mathrm{w}$ postinfection and then tended to downregulate with levels close to Ctrl values by treatment. For the majority of these proteins, the trend was high expression by the E6w group. They are involved in the early stages of immune responses to Schistosoma infection. GO analysis indicated that some of these proteins represent innate immune response, receptor-mediated endocytosis, and transport (Figure 4).

Proteins annotated to receptor-mediated endocytosis included hemopexin, galectin-3-binding protein, apolipoprotein $\mathrm{B}$, and monocyte differentiation antigen CD14. Proteins annotated to innate immune response included monocyte differentiation antigen CD14, Ig mu chain C region-secreted form, and fibrinogen alpha-chain. Nearly half of these proteins are involved in hydrolase activity, metal ion binding, and protein binding. Among the eight clusters, there were few changes in cellular components, which were concentrated in extracellular exosome, extracellular space, and extracellular region. Only cluster 3 proteins participated in the cytoplasm, extracellular exosome, and nucleus. We enriched the DEPs between each of two consecutive groups into GO terms and found that molecular function differentially changed, but there was no significant difference between cell component and biological process (Figure 5). During the first week of infection, there was a negative regulation of endopeptidase activity. With the progress of infection and treatment, the immune system gradually changed from an innate immune response to an inflammatory response and acute-phase response. The cell components of most 


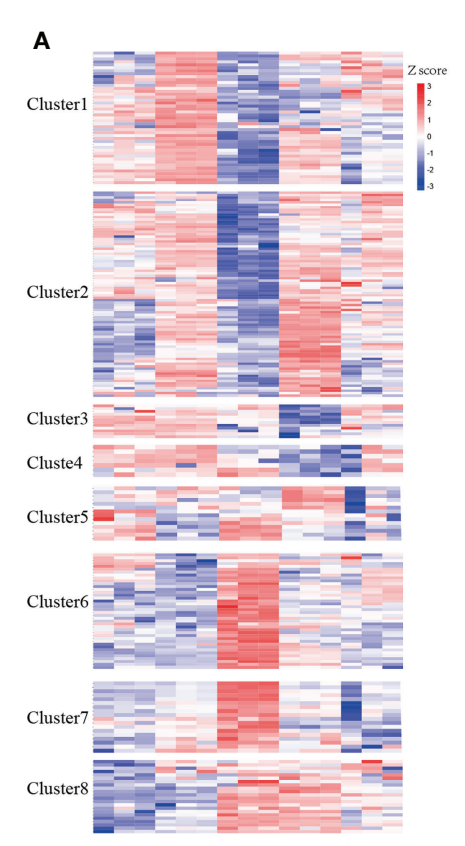

B
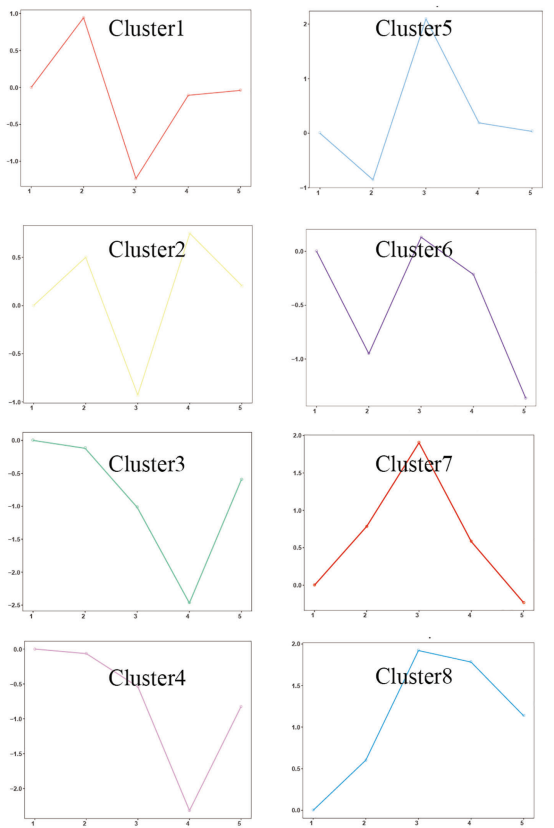

FIGURE 3 | Temporal analysis of DEPs. (A) DEPs were clustered by Z-score. (B) The $\log _{2}$ FC of proteins in eight clusters was quantified. The solid colored line represents the average value of the ratio between the experimental group and the control group.

proteins were enriched in the extracellular region, extracellular space, and extracellular exosome, and most of the molecular functions were protein binding and hydrolase activity.

\section{DISCUSSION}

In this study, the protein expression profile of serum during $S$. japonicum infection and treatment in the animal model was analyzed by label-free quantitative proteomics, and 396 host proteins were further filtered by MaxQuant search. Through these approaches, useful for investigating large numbers of proteins over several time points during infection and treatment, we identified proteins that are likely involved in the infection process in Schistosoma. Identifying these proteins in Schistosoma samples can provide potential biomarkers for detection and diagnosis. One benefit of our results is that Schistosoma infection can be used to discover proteins important in host defense, as parasite modulation of protein expression generally reflects a biological imperative.

S. japonicum migrates to various organs through blood and secretes a large amount of protein during the process. CCA and CAA of $S$. mansoni are also excreta such as that produced by $S$. japonicum migration in blood vessels and have been used diagnostically (Deelder et al., 1980; Casacuberta et al., 2016), and therefore, searching for potential biomarkers in serum is a method with diagnostic potential. Due to the low content of these circulating antigens in the host, most of them are mixtures, so the key proteins have not been further studied. Excretory and secretory proteins (ESP) from Schistosoma are also a kind of secreted protein with the migration of blood in the host; the supernatant was obtained from different development stages cultured (Mathieson and Wilson, 2010; Cao et al., 2016b; De Marco Verissimo et al., 2019). Through quantitative analysis of the excretory/secretory proteome of the adult (Liu et al., 2009; Hong et al., 2013), it is found that the main components of fatty acid-binding proteins and heat shock proteins HSP70, HSP90, and HSP97 constitute the largest protein family in the ES proteome, which means that these proteins play a central role in immune regulation in the host relationship. ESPs also included actins, tubulins, and 14-3-3. In the present study, 10 proteins derived confidently from $S$. japonicum, including tubulin, calmodulin, EF-hand domain-containing protein, and SJCHGC06596 protein. Proteins with high homology with rabbit such as actin 5c, Histone H4, and HSP 70 were also detected and are highly abundant. HSP70 participates in egg skeleton formation (Dewalick et al., 2011), while HSP70, 90, and actin still exist in isolated exosomes (Zhu et al., 2016). A protein chip method was used to predict the interaction of the three heat shock proteins SjHSP40, SjHSP70, and SjHSP90 with SjSTIP1 through bioinformatics, together with SjPPase as a drug or vaccine target, which has potential diagnostic or therapeutic value (Chen et al, 2014). Histone $\mathrm{H} 4$ and $\mathrm{H} 2$ were also identified in the serum after infection. Histone and histone-modified proteins have great influence on $\mathrm{H} 4$ and $\mathrm{H} 2$ in parasites with complex life cycles and multiple developmental stages (Fioravanti et al., 2020). Studies have shown that these conserved proteins play an important role as 
A

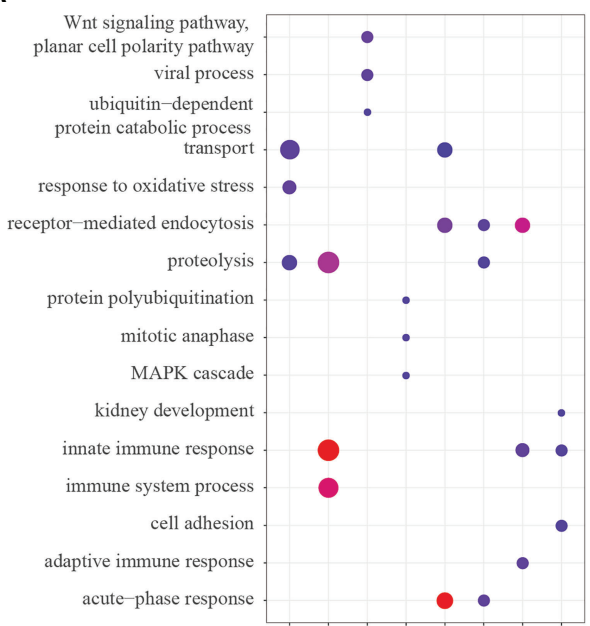

C

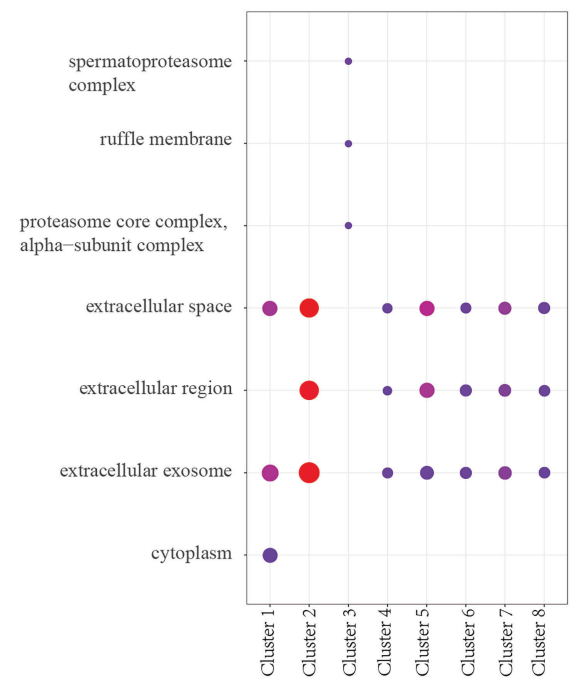

B

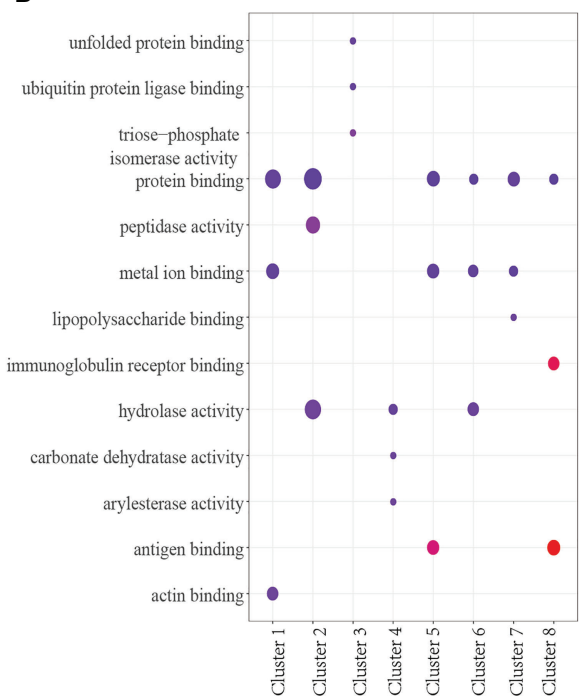

$\begin{array}{llll}0 & 4 & 8 & 16\end{array}-\log _{10}(\mathrm{q}$-value $)$

000 Number

FIGURE 4 | (A-C) GO analysis of the top three terms between Biological Process (A), Molecular Function (B), and Cell Component (C) in eight clusters.

parasites rapidly adapt to different host environments, evade host immune responses, or change their phenotypes during several critical periods (Batugedara et al., 2017).

Recent study has identified a large number of proteins with immunomodulatory activity by comparing the ESP proteomics of three species from S. mansoni, S. japonicum, and S. haematobium and found that the three species have low homology and differences in content (Carson et al., 2020). Further study between these components may identify new proteins including their function or interaction with hosts. In recent studies, a small part of eggrelated proteins was found in the ESP of S. japonicum, indicating that the ESP can stimulate the innate and adaptive immune system in several different ways. Quantitative SWATH analysis revealed that mature eggs are more likely to stimulate the host immune response than immature eggs (De Marco Verissimo et al., 2019).
The bioinformatics analysis of ESPs in schistosomula and adult worms showed that the upregulated differential ESPs in schistosomula were related to stress response, carbohydrate metabolism, and protein degradation, while the upregulated ESPs in adults were mainly related to immune regulation and purine metabolism (Cao et al., 2016b). Actin can form microfilaments with myosin (Reymann et al., 2012) so that the cercariae of S. japonicum can better adhere to the muscles during exercise (Mair et al., 2003). Some studies have analyzed the differences between females and males of Schistosoma (Cheng et al., 2005; Tallima and El, 2007; Reamtong et al., 2020). It was found that males tend to participate in the actin filamentation process, microtubule process, biosynthesis process, and homeostasis process (Reamtong et al., 2020). Similarly, proteins from males are involved in the proteasome core complex, intracellular signal transduction, and actin polymerization 


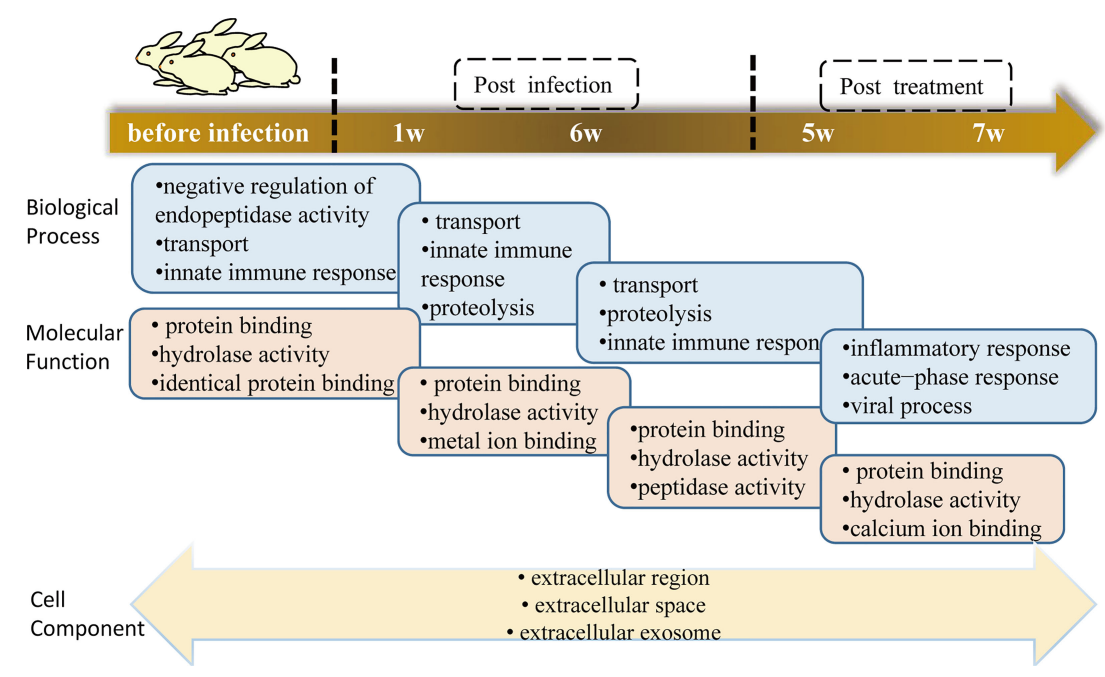

FIGURE 5 | GO terms of DEPs between two consecutive groups.

regulation (Tallima and El, 2007). The role of actin in male or various developmental stages is worthy of further study. The binding of praziquantel to $S$. japonicum actin may cause molecular conformational change (Tallima and El, 2007) that severely affects the function of actin-binding proteins and leads to the destruction of worm integrity (Linder and Thors, 1992). Actin may also be a suitable drug target for S. japonicum.

Previous studies have focused on Schistosoma-derived protein to understand how Schistosoma causes damage. S. japonicum cercariae invade the host and develop into an immature worm. At this stage, the worm is small and fragile and is an ideal target for host immune attack (Cao et al., 2016a) and is important for early detection. After approximately 3 weeks, the worm grows into an adult, migrates to the portal vein-mesenteric vein system for male and female mating, produces a large number of eggs, and gathers on the liver to form granuloma, causing serious damage to the liver. Eggs can be found in feces at the beginning of 5 weeks. At this time, if treatment is not timely, patients with severe infection begin to develop liver fibrosis and other organ damage that is difficult to alleviate. Due to the phenomenon of immune evasion (McKee and Pearce, 2004) by $S$. japonicum, early detection of $S$. japonicum is particularly difficult, especially in areas with low epidemic levels. S. japonicum tegument protein phosphoglycerate mutase (SjPGM) has been identified as a potential disease diagnostic marker (Zhang et al., 2015). Specific IgG antibodies to rSjPGM in the sera of rabbits 2 weeks postinfection increased and then declined gradually from 2 months after praziquantel treatment. The sensitivity and specificity were high, and cross-reactivity of rSjPGM-ELISA in the detection of was low. In S. haematobium, Onile et al. (2017) tested and identified potential biomarkers in human urine and identified some potential targets for the diagnosis and treatment of $S$. haematobium. Kardoush et al. (2016) tested and identified potential biomarkers in S. mansoni using three mass spectrometry platforms and verified glutathione $S$ transferase (GST:25KDa) by a Western blot method, which confirmed its potential diagnostic value. Subsequent studies also found that glutathione S-transferase can defend against nonspecific oxidation-induced immune attack ( $\mathrm{Li}$ et al., 2020) of $S$. mansoni. The proteins detected in serum may play an important role in the pathological changes of schistosomiasis. These potential biomarkers may provide a theoretical basis for diagnosis or treatment.

The effect of S. japonicum infection and treatment on the host has not previously been studied further. In this study, we selected five time points: non-infection, 1 week and 6 weeks after infection, and 5 weeks and 7 weeks after treatment, and the differential protein began to increase from 1 week after infection, reached the maximum at 6 weeks after infection, and gradually increased with the increase in infection time. After treatment, the differential protein began to decrease with the increase in treatment time, and it was found that the up- and downregulated proteins significantly decreased at 7 weeks after treatment. GO enrichment analyses identified numerous biological processes that are consistent with Schistosoma infection and treatment. For example, several biological processes were enriched by proteins that changed during infection or treatment in our study, including receptor-mediated endocytosis, innate immune response, and adaptive immune response. Corresponding to the changes in the protein temporal spectrum in this study, we detected some acute-phase proteins among clusters $5,6,7$, and 8 that were differentially expressed between the infection and treatment groups, especially the proteins in cluster 7 , which can be used as potential biomarkers (Table 2). The results showed that compared with the other three groups, the entire protein at 7 weeks after treatment was similar with that of the control group. This is mainly due to the fact that schistosomiasis is dominated by the Th1 immune response at $6-$ 8 weeks and then reaches a peak (Rabello, 1995), and subsequently, a large number of pro-inflammatory cytokines such as tumor necrosis factor, interleukin-1, and interleukin-6 appear (de Jesus et al., 2002). GO analysis also validates this hypothesis because Schistosoma 
TABLE 2 | Eighteen host proteins in cluster 7 can be potential biomarkers.

\begin{tabular}{|c|c|c|c|c|c|c|}
\hline Protein IDs & Protein names & GenBank IDs & $\begin{array}{l}\text { Peptide } \\
\text { counts }\end{array}$ & $\begin{array}{l}\text { Unique } \\
\text { peptides }\end{array}$ & $\begin{array}{c}\text { Sequence } \\
\text { coverage } \\
{[\%]}\end{array}$ & Score \\
\hline G1TVS4 & Hemopexin & AAGW02008019.1;AAGW02008020.1 & 39 & 7 & 69.8 & 323 \\
\hline G1TFU9 & Galectin-3-binding protein & & 23 & 23 & 49.4 & 323 \\
\hline G1U9R4 & Apolipoprotein B & $\begin{array}{l}\text { AAGW02055051.1; AAGW02055052.1;AAGW02055053.1; } \\
\text { AAGW02055054.1;AAGW02055055.1; AAGW02055056.1; } \\
\text { AAGW02055057.1 }\end{array}$ & 157 & 154 & 45.8 & 323 \\
\hline A0A5F9D585 & $\begin{array}{l}\text { Mannan-binding lectin serine } \\
\text { peptidase } 1\end{array}$ & AAGW02014015.1;AAGW02014016.1 & 23 & 9 & 47.7 & 323 \\
\hline A0A5F9C8F6 & Tenascin C & & 70 & 70 & 47.5 & 323 \\
\hline G1SLB5 & $\begin{array}{l}\text { Monocyte differentiation } \\
\text { antigen CD14 }\end{array}$ & AAGW02027693.1 & 9 & 9 & 36.3 & 178 \\
\hline A0A5F9CTN2 & $\begin{array}{l}\text { Transforming growth factor- } \\
\text { beta-induced protein ig-h3 }\end{array}$ & AAGW02027826.1;AAGW02027827.1 & 13 & 13 & 30.1 & 86 \\
\hline P03988 & $\begin{array}{l}\text { Ig mu chain C region } \\
\text { secreted form }\end{array}$ & K01357.1 & 19 & 2 & 55.9 & 323 \\
\hline Q865F2 & Adhesion molecule VCAM-1 & AY212510.1 & 32 & 1 & 59.4 & 242 \\
\hline Q7M322 & Plasmin & & 1 & 1 & 57.6 & 216 \\
\hline A0A5F9C4W7 & $\begin{array}{l}\text { SERPIN domain-containing } \\
\text { protein }\end{array}$ & AAGW02039505.1 & 8 & 4 & 29.3 & 20 \\
\hline G1TV79 & Collagen-binding protein & AAGW02008237.1 & 8 & 4 & 50.2 & 108 \\
\hline G1TOX2 & Fibrinogen alpha chain & AAGW02045946.1 & 24 & 24 & 44.9 & 323 \\
\hline G1T763 & $\begin{array}{l}\text { Polymeric immunoglobulin } \\
\text { receptor }\end{array}$ & AAGW02025413.1 & 28 & 3 & 50.6 & 10 \\
\hline G1U7S4 & Phosphoglycerate mutase & AAGW02061870.1 & 5 & 4 & 20.6 & 11 \\
\hline Q6B736 & $\begin{array}{l}\text { Immunglobulin heavy chain } \\
\text { variable region }\end{array}$ & AY676737.1 & 3 & 1 & 37.1 & 34 \\
\hline A0A5F9CIB4 & Uromodulin & AAGW02057059.1 & 8 & 8 & 14.8 & 86 \\
\hline A0A5F9C9Q2 & $\begin{array}{l}\text { Collagen type III alpha } 1 \\
\text { chain }\end{array}$ & AAGW02003526.1 & 8 & 8 & 7.7 & 92 \\
\hline
\end{tabular}

infection is immunomodulatory, and therefore, we were not surprised to observe that proteins in the acute inflammatory response were regulated.

In the present study, proteins annotated to immune response processes were at the highest levels during infection, with lower levels during treatment. Eight weeks after treatment with praziquantel, the number of eggs greatly decreased, and the disease was in a recovery state (Mnkugwe et al., 2020). The role of these proteins in immune response function requires further investigation but conceivably could be similar to their role in Schistosoma-induced infection. The upregulated differential proteins such as immunoglobulin also participate in the immune response in the functional enrichment of GO, and therefore, the increase is more obvious at 6 weeks after infection. Mannan binding lectin serine peptidase 1 (MASP1) in cluster 7 plays a key role in immune function. Schistosoma carries glyconjugates at every stage and interacts with mannosebinding lectin (MBL), an innate immune recognition element (Antony et al., 2013). MBL with associated MASP1 and MASP2 interacts with the tegument of Schistosoma and activates complement cascades (Klabunde et al., 2000; Antony et al., 2013). The main pathological features of schistosomiasis liver fibrosis are the proliferation of hepatic stellate cells (HSCs) and the deposition of collagen type I ( $\mathrm{Col} \mathrm{I}$ ) and collagen type III (Col III) (Chu et al., 2007). The content of collagen increased significantly with the time of infection with S. japonicum, and the synthesis of collagen related to liver and granuloma changed to type III collagen (Olds et al., 1985). The dynamic change of collagen type III identified from host proteins was similar to the previous study that up-graduated 1 week after infection and which supposed to be down-graduated after PZQ treatment.

The current study shows that label-free quantitative proteomics is a promising method for identifying antigens involved in schistosomiasis. In our analysis of host differential proteins, we found that the main molecular functions of proteins in the differential analysis groups were protein binding and protease hydrolysis. In the biological process, the main functions were mainly transport, protein hydrolysis, and intracellular immunity, which are related to the acute inflammatory reaction of $S$. japonicum infection. After infection, the high expression of protein binding, hydrolysis, transport, and the metal ion-binding pathway is conducive to protein synthesis to meet the immune needs of the body. We also found that the expression of the many host proteins was decreased after infection, and this may be related to the decrease in the expression of key proteins after severe infection. Our study suggests that additional characteristic molecular changes at protein levels may be used to build a diagnostic model for identification of early cases. Our data elucidate the molecular changes reflected in Schistosoma serum, which can potentially yield critical diagnostic markers or therapeutic targets for managing severe Schistosoma patients.

Although the genome of S. japonicum was sequenced in 2009 and 2019 (Schistosoma japonicum Genome and Functional Analysis, 2009; Luo et al., 2019), the function of many proteins is still unknown or unpredicted. The current study is a preliminary examination of the host serum of Schistosoma japonicum infection, 
and the difference analysis and time series analysis of the proteins involved will continue to determine the biomarkers that play a key role in early infection and curative effect assessment. The identified proteins related to $S$. japonicum can be used as markers for the diagnosis of schistosomiasis. In previous reports, these proteins have been used as markers to verify that they can be used as potential biomarkers, and thus, they are reliable for identifying relevant diagnostic or therapeutic markers through a proteome. Serum proteomics is a method used to identify disease biomarkers, and it has been used in many diseases, with many results obtained. As a parasite in blood vessels, S. japonicum is still valuable as a satisfactory research subject (Zhong et al., 2017) because of its availability and stability, and the ability to directly observe the changes in its body, although it is difficult to quantify its source protein in the host serum. In this study, the differential proteins produced during the pathological changes of S. japonicum were analyzed by comparative proteomics at multiple time points of infection and treatment of S. japonicum, which is a feasible method for identifying biomarkers.

There are more than 40 types of natural hosts of S. japonicum, among which rabbit is a classical animal model for $S$. japonicum infection with cercariae that is used in a variety of studies (Guo et al., 2012; Huang et al., 2020). Liu et al. (2015) found that the transcriptional profiles of S. japonicum in four different hosts were basically the same by comparing the $S$. japonicum gene expression profiles of experimental animal hosts (BALB/c mice, C57BL/6 mice, and rabbits) and natural hosts (water buffalo). In view of the high sensitivity of rabbits to pathogens and the similarity of disease pathology between humans and rabbits (Tran et al., 2020), the New Zealand rabbit was used as the animal model in this experiment, and it was easy to set the time points for infection and treatment and control the intervention conditions. Therefore, it is necessary for a large number of verification tests to be carried out to extend the results to the human body. We focused on host proteins because they play a critical role in repair of infection and cure. However, our study does not capture the complex interactions between host and Schistosoma-derived proteins. Proteomics analysis in this study does not serve as an absolute quantification. If the model is to be clinically applied, additional validation of these proteins will be required. The impact of drugs, including praziquantel, on proteomic profiles also requires evaluation. The serum samples were collected at different time points along the disease course, and they can potentially be utilized to explore protein expression changes. Due to the small sample size, future studies on serum from additional time points are required for rigorous temporal analysis.

\section{CONCLUSION}

Herein, we presented a label-free LC-MS/MS shotgun proteomics approach for biomarkers to distinguish $S$. japonicum infection between the early stage and the course of treatment. This study provides the comprehensive experimental temporal serum proteomics that can be used for early detection of the identified proteins. We identified a number of core factors by GO analysis, and some of them were previously uncharacterized proteins in host proteins. In conclusion, this study presents a systematic proteomic investigation of serum samples from infection groups and treatment groups.

In this work, we found a total of 10 proteins derived from $S$. japonicum and described the expression changes of more than 200 host proteins during five stages of Schistosoma infections and treatment. Eighteen host proteins such as mannan-binding lectin serine peptidase 1, immunoglobulin, and collagen can be used as potential biomarkers. These provide a comprehensive landscape of the proteome of Schistosoma with direct insight into the protein changes affecting the regulation of the infection process. Our data offer a landscape view of serum protein changes induced by Schistosoma infection, which may provide useful diagnostic and therapeutic clues for S. japonicum.

\section{DATA AVAILABILITY STATEMENT}

The mass spectrometry proteomics data are available in the ProteomeXchange Consortium via the PRIDE partner repository with the dataset identifier PXD029635.

\section{ETHICS STATEMENT}

The animal study was reviewed and approved by the Ethical Review Committee of Jiangsu Institute of Parasitic Diseases.

\section{AUTHOR CONTRIBUTIONS}

KY and G-LY designed the study. N-NB and SZ performed the experiment. SZ and J-FZ conducted the experimental infection of the rabbits. N-NB and YC performed the proteomics assay. N$\mathrm{NB}, \mathrm{SZ}$, and C-YZ conducted the proteomic data analysis. N-NB, $\mathrm{KY}$, and G-LY wrote the article. All authors contributed to the article and approved the submitted version.

\section{FUNDING}

This research was funded by the grants from the National Natural Science Foundation of China, grant number 82173586, and Jiangsu Provincial Department of Science and Technology, grant number BZ2020003.

\section{ACKNOWLEDGMENTS}

We would like to thank Professor Xiao-Dong Gao (Jiangnan University) for his support for experiments and instruments.

\section{SUPPLEMENTARY MATERIAL}

The Supplementary Material for this article can be found online at: https://www.frontiersin.org/articles/10.3389/fcimb.2021. 784279/full\#supplementary-material

Supplementary Table 1 | GO enrichment of host protein and DEPs.

Supplementary Table 2 | Output of proteins identified from S. japonicum by MaxQuant. 


\section{REFERENCES}

Antony, J. S., Ojurongbe, O., van Tong, H., Ouf, E. A., Engleitner, T., Akindele, A. A., et al. (2013). Mannose-Binding Lectin and Susceptibility to Schistosomiasis. J. Infect. Dis. 207 (11), 1675-1683. doi: 10.1093/infdis/jit081

Batugedara, G., Lu, X. M., Bunnik, E. M., and Le Roch, K. G. (2017). The Role of Chromatin Structure in Gene Regulation of the Human Malaria Parasite. Trends Parasitol 33 (5), 364-377. doi: 10.1016/j.pt.2016.12.004

Bergquist, R., Johansen, M. V., and Utzinger, J. (2009). Diagnostic Dilemmas in Helminthology: What Tools to Use and When? Trends Parasitol 25 (4), 151156. doi: 10.1016/j.pt.2009.01.004

Bojkova, D., Klann, K., Koch, B., Widera, M., Krause, D., Ciesek, S., et al. (2020). Proteomics of SARS-CoV-2-Infected Host Cells Reveals Therapy Targets. Nature 583 (7816), 469-472. doi: 10.1038/s41586-020-2332-7

Cao, X., Fu, Z., Zhang, M., Han, Y., Han, H., Han, Q., et al. (2016a). iTRAQ-Based Comparative Proteomic Analysis of Excretory Secretory Proteins of Schistosomula and Adult Worms of Schistosoma Japonicum. J. Proteomics 138, 30-39. doi: 10.1016/j.jprot.2016.02.015

Cao, X., Fu, Z., Zhang, M., Han, Y., Han, Q., Lu, K., et al. (2016b). Excretory/ secretory Proteome of 14-Day Schistosomula, Schistosoma Japonicum. J. Proteomics 130, 221-230. doi: 10.1016/j.jprot.2015.10.001

Carson, J. P., Ramm, G. A., Robinson, M. W., McManus, D. P., and Gobert, G. N. (2018). Schistosome-Induced Fibrotic Disease: The Role of Hepatic Stellate Cells. Trends Parasitol 34 (6), 524-540. doi: 10.1016/j.pt.2018.02.005

Carson, J. P., Robinson, M. W., Hsieh, M. H., Cody, J., Le, L., You, H., et al. (2020). A Comparative Proteomics Analysis of the Egg Secretions of Three Major Schistosome Species. Mol. Biochem. Parasitol. 240, 111322. doi: 10.1016/ j.molbiopara.2020.111322

Casacuberta, M., Kinunghi, S., Vennervald, B. J., and Olsen, A. (2016). Evaluation and Optimization of the Circulating Cathodic Antigen (POC-CCA) Cassette Test for Detecting Schistosoma Mansoni Infection by Using Image Analysis in School Children in Mwanza Region, Tanzania. Parasite Epidemiol. Control 1 (2), 105-115. doi: 10.1016/j.parepi.2016.04.002

Cheng, G. F., Lin, J. J., Feng, X. G., Fu, Z. Q., Jin, Y. M., Yuan, C. X., et al. (2005). Proteomic Analysis of Differentially Expressed Proteins Between the Male and Female Worm of Schistosoma Japonicum After Pairing. Proteomics 5 (2), 511521. doi: 10.1002/pmic.200400953

Chen, J. H., Zhang, T., Ju, C., Xu, B., Lu, Y., Mo, X. J., et al. (2014). An Integrated Immunoproteomics and Bioinformatics Approach for the Analysis of Schistosoma Japonicum Tegument Proteins. J. Proteomics 98, 289-299. doi: 10.1016/j.jprot.2014.01.010

Chu, D., Luo, Q., Li, C., Gao, Y., Yu, L., Wei, W., et al. (2007). Paeoniflorin Inhibits TGF-Beta1-Mediated Collagen Production by Schistosoma Japonicum Soluble Egg Antigen In Vitro. Parasitology 134 (Pt 11), 1611-1621. doi: 10.1017/ S0031182007002946

Conesa, A., Gotz, S., Garcia-Gomez, J. M., Terol, J., Talon, M., and Robles, M. (2005). Blast2GO: A Universal Tool for Annotation, Visualization and Analysis in Functional Genomics Research. Bioinformatics 21 (18), 36743676. doi: 10.1093/bioinformatics/bti610

Cox, J., Hein, M. Y., Luber, C. A., Paron, I., Nagaraj, N., and Mann, M. (2014). Accurate Proteome-Wide Label-Free Quantification by Delayed Normalization and Maximal Peptide Ratio Extraction, Termed MaxLFQ. Mol. Cell Proteomics 13 (9), 2513-2526. doi: 10.1074/mcp.M113.031591

Deelder, A. M., Kornelis, D., Van Marck, E. A., Eveleigh, P. C., and Van Egmond, J. G. (1980). Schistosoma Mansoni: Characterization of Two Circulating Polysaccharide Antigens and the Immunological Response to These Antigens in Mouse, Hamster, and Human Infections. Exp. Parasitol 50 (1), 16-32. doi: 10.1016/0014-4894(80)90004-1

de Jesus, A. R., Silva, A., Santana, L. B., Magalhaes, A., de Jesus, A. A., de Almeida, R. P., et al. (2002). Clinical and Immunologic Evaluation of 31 Patients With Acute Schistosomiasis Mansoni. J. Infect. Dis. 185 (1), 98-105. doi: 10.1086/324668

De Marco Verissimo, C., Potriquet, J., You, H., McManus, D. P., Mulvenna, J., and Jones, M. K. (2019). Qualitative and Quantitative Proteomic Analyses of Schistosoma Japonicum Eggs and Egg-Derived Secretory-Excretory Proteins. Parasites Vectors 12 (1), 173-116. doi: 10.1186/s13071-019-3403-1

Dewalick, S., Bexkens, M. L., van Balkom, B. W., Wu, Y. P., Smit, C. H., Hokke, C. H., et al. (2011). The Proteome of the Insoluble Schistosoma Mansoni Eggshell Skeleton. Int. J. Parasitol 41 (5), 523-532. doi: 10.1016/j.ijpara.2010.12.005
Fioravanti, R., Mautone, N., Rovere, A., Rotili, D., and Mai, A. (2020). Targeting Histone Acetylation/Deacetylation in Parasites: An Updat-2020). Curr. Opin. Chem. Biol. 57, 65-74. doi: 10.1016/j.cbpa.2020.05.008

Geyer, P. E., Holdt, L. M., Teupser, D., and Mann, M. (2017). Revisiting Biomarker Discovery by Plasma Proteomics. Mol. Syst. Biol. 13 (9), 942. doi: 10.15252/ msb.20156297

Gryseels, B., Polman, K., Clerinx, J., and Kestens, L. (2006). Human Schistosomiasis. Lancet 368 (9541), 1106-1118. doi: 10.1016/S0140-6736(06)69440-3

Guo, J. J., Zheng, H. J., Xu, J., Zhu, X. Q., Wang, S. Y., and Xia, C. M. (2012). Sensitive and Specific Target Sequences Selected From Retrotransposons of Schistosoma Japonicum for the Diagnosis of Schistosomiasis. PloS Negl. Trop. Dis. 6 (3), e1579. doi: 10.1371/journal.pntd.0001579

He, P., Gordon, C. A., Williams, G. M., Li, Y., Wang, Y., Hu, J., et al. (2018). RealTime PCR Diagnosis of Schistosoma japonicum in Low Transmission Areas of China. Infect Dis Poverty 7 (1), 8. doi: 10.1186/s40249-018-0390-y

Hong, Y., Sun, A., Zhang, M., Gao, F., Han, Y., Fu, Z., et al. (2013). Proteomics Analysis of Differentially Expressed Proteins in Schistosomula and Adult Worms of. Schistosoma japonicum Acta Trop. 126 (1), 1-10. doi: 10.1016/ j.actatropica.2012.12.009

Huang, P., Zhou, M., Cheng, S., Hu, Y., Gao, M., Ma, Y., et al. (2020). Myricetin Possesses Anthelmintic Activity and Attenuates Hepatic Fibrosis via Modulating TGFbeta1 and Akt Signaling and Shifting Th1/Th2 Balance in Schistosoma Japonicum-Infected Mice. Front. Immunol. 11, 593. doi: 10.3389/ fimmu.2020.00593

Hu, Y., Chen, J., Xu, Y., Zhou, H., Huang, P., Ma, Y., et al. (2020). Alterations of Gut Microbiome and Metabolite Profiling in Mice Infected by Schistosoma Japonicum. Front. Immunol. 11, 569727. doi: 10.3389/ fimmu.2020.569727

Karczewski, K. J., and Snyder, M. P. (2018). Integrative Omics for Health and Disease. Nat. Rev. Genet. 19 (5), 299-310. doi: 10.1038/nrg.2018.4

Kardoush, M. I., Ward, B. J., and Ndao, M. (2016). Identification of Candidate Serum Biomarkers for Schistosoma Mansoni Infected Mice Using Multiple Proteomic Platforms. PloS One 11 (5), e0154465. doi: 10.1371/ journal.pone.0154465

Klabunde, J., Berger, J., Jensenius, J. C., Klinkert, M. Q., Zelck, U. E., Kremsner, P. G., et al. (2000). Schistosoma Mansoni: Adhesion of Mannan-Binding Lectin to Surface Glycoproteins of Cercariae and Adult Worms. Exp. Parasitol 95 (4), 231-239. doi: 10.1006/expr.2000.4539

Linder, E., and Thors, C. (1992). Schistosoma Mansoni: Praziquantel-Induced Tegumental Lesion Exposes Actin of Surface Spines and Allows Binding of Actin Depolymerizing Factor, Gelsolin. Parasitology 105 (Pt 1), 71-79. doi: 10.1017/s0031182000073704

Li, X., Qiao, H., Qin, F., Cheng, G., Liu, J., Li, H., et al. (2020). Comparative Analysis of iTRAQ-Based Proteome Profiles of Schistosoma Japonicum Female Worms Coming From Single-Sex Infections and Bisexual Infections. J. Proteomics 213, 103597. doi: 10.1016/j.jprot.2019.103597

Liu, F., Cui, S. J., Hu, W., Feng, Z., Wang, Z. Q., and Han, Z. G. (2009). Excretory/ secretory Proteome of the Adult Developmental Stage of Human Blood Fluke, Schistosoma Japonicum. Mol. Cell Proteomics 8 (6), 1236-1251. doi: 10.1074/ mcp.M800538-MCP200

Liu, S., Zhou, X., Piao, X., Wu, C., Hou, N., and Chen, Q. (2015). Comparative Analysis of Transcriptional Profiles of Adult Schistosoma Japonicum From Different Laboratory Animals and the Natural Host, Water Buffalo. PloS Negl. Trop. Dis. 9 (8), e0003993. doi: 10.1371/journal.pntd.0003993

LoVerde, P. T. (2019). Schistosomiasis. Adv. Exp. Med. Biol. 1154, 45-70. doi: 10.1007/978-3-030-18616-6_3

Luo, F., Yin, M., Mo, X., Sun, C., Wu, Q., Zhu, B., et al. (2019). An Improved Genome Assembly of the Fluke Schistosoma Japonicum. PloS Negl. Trop. Dis. 13 (8), e0007612. doi: 10.1371/journal.pntd.0007612

Mair, G. R., Maule, A. G., Fried, B., Day, T. A., and Halton, D. W. (2003). Organization of the Musculature of Schistosome Cercariae. J. Parasitol 89 (3), 623-625. doi: 10.1645/0022-3395(2003)089[0623:OOTMOS]2.0.CO;2

Mathieson, W., and Wilson, R. A. (2010). A Comparative Proteomic Study of the Undeveloped and Developed Schistosoma Mansoni Egg and its Contents: The Miracidium, Hatch Fluid and Secretions. Int. J. Parasitol 40 (5), 617-628. doi: 10.1016/j.ijpara.2009.10.014

McKee, A. S., and Pearce, E. J. (2004). CD25+CD4+ Cells Contribute to Th2 Polarization During Helminth Infection by Suppressing Th1 Response 
Development. J. Immunol. 173 (2), 1224-1231. doi: 10.4049/ jimmunol.173.2.1224

McManus, D. P., Dunne, D. W., Sacko, M., Utzinger, J., Vennervald, B. J., and Zhou, X. N. (2018). Schistosomiasis. Nat. Rev. Dis. Primers 4 (1):13. doi: 10.1038/s41572-018-0013-8

Mnkugwe, R. H., Minzi, O., Kinung'hi, S., Kamuhabwa, A., and Aklillu, E. (2020). Efficacy and Safety of Praziquantel and Dihydroartemisinin Piperaquine Combination for Treatment and Control of Intestinal Schistosomiasis: A Randomized, non-Inferiority Clinical Trial. PloS Negl. Trop. Dis. 14 (9), e0008619. doi: 10.1371/journal.pntd.0008619

Olds, G. R., Griffin, A., and Kresina, T. F. (1985). Dynamics of Collagen Accumulation and Polymorphism in Murine Schistosoma Japonicum. Gastroenterology 89 (3), 617-624. doi: 10.1016/0016-5085(85)90459-7

Onile, O. S., Calder, B., Soares, N. C., Anumudu, C. I., and Blackburn, J. M. (2017). Quantitative Label-Free Proteomic Analysis of Human Urine to Identify Novel Candidate Protein Biomarkers for Schistosomiasis. PloS Neglected Trop. Dis. 11 (11), e0006045. doi: 10.1371/journal.pntd.0006045

Park, J. H., Qiu, Y., and Herbordt, M. C. (2009). “'CAAD BLASTP: NCBI BLASTP Accelerated With FPGA-Based Accelerated Pre-Filtering"," in 2009 17th IEEE Symposium on Field Programmable Custom Computing Machines.). Napa, CA, USA: IEEE. doi: 10.1109/FCCM.2009.27

Perez-Riverol, Y., Csordas, A., Bai, J., Bernal-Llinares, M., Hewapathirana, S., Kundu, D. J., et al. (2019). The PRIDE Database and Related Tools and Resources in 2019: Improving Support for Quantification Data. Nucleic Acids Res. 47 (D1), D442-D450. doi: 10.1093/nar/gky1106

Puray-Chavez, M., LaPak, K. M., Schrank, T. P., Elliott, J. L., Bhatt, D. P., Agajanian, M. J., et al. (2021). Systematic Analysis of SARS-CoV-2 Infection of an ACE2-Negative Human Airway Cell. Cell Rep. 36 (2), 109364. doi: 10.1016/j.celrep.2021.109364

Rabello, A. (1995). Acute Human Schistosomiasis Mansoni. Mem Inst Oswaldo Cruz 90 (2), 277-280. doi: 10.1590/s0074-02761995000200026

Reamtong, O., Simanon, N., Thiangtrongjit, T., Limpanont, Y., Chusongsang, P., Chusongsang, Y., et al. (2020). Proteomic Analysis of Adult Schistosoma Mekongi Somatic and Excretory-Secretory Proteins. Acta Tropica 202, 105247. doi: 10.1016/j.actatropica.2019.105247

Reymann, A. C., Boujemaa-Paterski, R., Martiel, J. L., Guerin, C., Cao, W., Chin, H. F., et al. (2012). Actin Network Architecture can Determine Myosin Motor Activity. Science 336 (6086), 1310-1314. doi: 10.1126/science.1221708

Schistosoma japonicum Genome, S and Functional Analysis, C (2009). The Schistosoma Japonicum Genome Reveals Features of Host-Parasite Interplay. Nature 460 (7253), 345-351. doi: 10.1038/nature08140

Schwamborn, K., Krieg, R. C., Grosse, J., Reulen, N., Weiskirchen, R., Knuechel, R., et al. (2009). Serum Proteomic Profiling in Patients With Bladder Cancer. Eur. Urol 56 (6), 989-996. doi: 10.1016/j.eururo.2009.02.031

Shiff, C., Veltri, R., Naples, J., Quartey, J., Otchere, J., Anyan, W., et al. (2006). Ultrasound Verification of Bladder Damage is Associated With Known Biomarkers of Bladder Cancer in Adults Chronically Infected With Schistosoma Haematobium in Ghana. Trans. R Soc. Trop. Med. Hyg 100 (9), 847-854. doi: 10.1016/j.trstmh.2005.10.010

Sotillo, J., Pearson, M., Becker, L., Mulvenna, J., and Loukas, A. (2015). A Quantitative Proteomic Analysis of the Tegumental Proteins From Schistosoma Mansoni Schistosomula Reveals Novel Potential Therapeutic Targets. Int. J. Parasitol 45 (8), 505-516. doi: 10.1016/ j.ijpara.2015.03.004
Tallima, H., and El, R. R. (2007). Praziquantel Binds Schistosoma Mansoni Adult Worm Actin. Int. J. Antimicrob. Agents 29 (5), 570-575. doi: 10.1016/ j.ijantimicag.2006.12.018

Tran, V. G., Venkatasubramaniam, A., Adhikari, R. P., Krishnan, S., Wang, X., Le, V. T. M., et al. (2020). Efficacy of Active Immunization With Attenuated Alpha-Hemolysin and Panton-Valentine Leukocidin in a Rabbit Model of Staphylococcus Aureus Necrotizing Pneumonia. J. Infect. Dis. 221 (2), 267275. doi: 10.1093/infdis/jiz437

van Dam, G. J., Bogitsh, B. J., van Zeyl, R. J., Rotmans, J. P., and Deelder, A. M. (1996). Schistosoma Mansoni: In Vitro and In Vivo Excretion of CAA and CCA by Developing Schistosomula and Adult Worms. J. Parasitol 82 (4), 557-564.

Weerakoon, K. G., Gordon, C. A., Cai, P., Gobert, G. N., Duke, M., Williams, G. M., et al. (2017). A Novel Duplex ddPCR Assay for the Diagnosis of Schistosomiasis Japonica: Proof of Concept in an Experimental Mouse Model. Parasitology 144 (8), 1005-1015. doi: 10.1017/S003118201700021X

Xing, Q. Q., Liu, L. W., Zhao, X., Lu, Y., Dong, Y. M., and Liang, Z. Q. (2019). Serum Proteomics Analysis Based on Label-Free Revealed the Protective Effect of Chinese Herbal Formula Gu-Ben-Fang-Xiao. BioMed. Pharmacother. 119, 109390. doi: 10.1016/j.biopha.2019.109390

Yang, G., Hu, Y., Sun, S., Ouyang, C., Yang, W., Wang, Q., et al. (2018). Comprehensive Glycoproteomic Analysis of Chinese Hamster Ovary Cells. Anal. Chem. 90 (24), 14294-14302. doi: 10.1021/acs.analchem.8b03520

Yu, J. M., de Vlas, S. J., Jiang, Q. W., and Gryseels, B.. (2007). Comparison of the Kato-Katz Technique, Hatching Test and Indirect Hemagglutination Assay (IHA) for the Diagnosis of Schistosoma japonicum Infection in China. Parasitol. Int. 56 (1), 45-49. doi: 10.1016/j.parint.2006.11.002

Zhang, M., Fu, Z., Li, C., Han, Y., Cao, X., Han, H., et al. (2015). Screening Diagnostic Candidates for Schistosomiasis From Tegument Proteins of Adult Schistosoma Japonicum Using an Immunoproteomic Approach. PloS Negl. Trop. Dis. 9 (2), e0003454. doi: 10.1371/journal.pntd.0003454

Zhong, Y., Guo, Y., Liu, X., Zhang, J., Ma, T., Shu, J., et al. (2017). Serum Glycopatterns as Novel Potential Biomarkers for Diagnosis of Acute-OnChronic Hepatitis B Liver Failure. Sci. Rep. 7, 45957. doi: 10.1038/srep45957

Zhu, L., Liu, J., Dao, J., Lu, K., Li, H., Gu, H., et al. (2016). Molecular Characterization of S. Japonicum Exosome-Like Vesicles Reveals Their Regulatory Roles in Parasite-Host Interactions. Sci. Rep. 6, 25885. doi: 10.1038/srep25885

Conflict of Interest: The authors declare that the research was conducted in the absence of any commercial or financial relationships that could be construed as a potential conflict of interest.

Publisher's Note: All claims expressed in this article are solely those of the authors and do not necessarily represent those of their affiliated organizations, or those of the publisher, the editors and the reviewers. Any product that may be evaluated in this article, or claim that may be made by its manufacturer, is not guaranteed or endorsed by the publisher.

Copyright $\odot 2021$ Bi, Zhao, Zhang, Cheng, Zuo, Yang and Yang. This is an openaccess article distributed under the terms of the Creative Commons Attribution License (CC BY). The use, distribution or reproduction in other forums is permitted, provided the original author(s) and the copyright owner(s) are credited and that the original publication in this journal is cited, in accordance with accepted academic practice. No use, distribution or reproduction is permitted which does not comply with these terms. 